\title{
LA INTIMIDACIÓN EN EL ÁMBITO BANCARIO COMO ILÍCITO AFECTANTE AL DERECHO CONSTITUCIONAL DE PROPIEDAD ${ }^{1}$
}

\author{
Intimidation as cause of nullity in bank contracting
}

\author{
Rubén Pérez Cordón \\ Magistrado Suplente de la Audiencia Provincial de Zamora \\ Profesor - Tutor de la UNED \\ rubperez@lugo.uned.es
}

\begin{abstract}
Silvia Martínez Cantón
Magistrada - juez titular del Juzgado de Primera Instancia $n^{\circ} 2$ de León

Profesora titular de Derecho Internacional Privado y Derecho Procesal en la Universidad Internacional de la Rioja

silvia.martinez@poderjudicial.es
\end{abstract}

http://dx.doi.org/10.18543/ed-68(2)-2020pp15-40

Recibido: 25.06 .2020

Aceptado: 14.10 .2020

\section{Resumen}

La figura de la intimidación resulta más habitual de lo que parece en el entorno de las relaciones comerciales y el ámbito bancario no es una excepción. El carácter de establecimiento público de las entidades financieras y su aparente formalidad no han sido óbice para que muchos clientes hayan aceptado, bajo intimidación, productos no deseados o cláusulas abusivas, que, en total libertad y existiendo alternativa, no

${ }^{1}$ En el presente trabajo se han utilizado los recursos facilitados por el Consejo de Europa a través de la Biblioteca del Tribunal Europeo de Derechos Humanos de Estrasburgo (Francia). 
habrían firmado. Estas conductas se han manifestado mayoritariamente en situaciones de renegociación contractual, en donde el cliente se veía inmerso en dificultades financieras que no dejaban más alternativa que aceptar una modificación de la situación contractual que mantenía con la entidad bancaria. Se trata de consentimientos impuestos y, por tanto, viciados, que se analizarán en el presente artículo.

\title{
Palabras clave
}

Coacción, intimidación, contratación bancaria, novación.

\begin{abstract}
Intimidation is far more common than it may seem in commercial relations environments and banking is no exception. The nature of public establishments of financial institutions and their assumed seriousness have not precluded that many clients have accepted, under intimidation, unwanted products or unfair terms, which, in a totally free scenario and with other alternatives to choose from, they would not have agreed to. These conducts have been manifested mostly in situations of renegotiation of contracts where clients were in financial hardship which forced them to accept a change in the terms they had with the bank. This type of consent is imposed and, thus, flawed and will be analyzed in this article.
\end{abstract}

\section{Keywords}

Coercion, intimidation, banking contracting, novation. 
SUMARIO: I. VOLUNTAD VICIADA Y NULIDAD. II. LA MAGNITUD DE LA INTIMIDACIÓN EN EL ÁMBITO CIVIL. III. LA INTIMIDACIÓN EN ÁMBITO BANCARIO DE LA RENEGOCIACIÓN. IV. CONClUSIONES. BibliogRAFÍA. JURISPRUDENCIA.

\section{VOLUNTAD VICIADA Y NULIDAD}

La figura de la coacción está regulada con diferentes efectos sancionadores o restrictivos para el autor en el orden civil y en el penal. En ambos ámbitos, la coacción presenta una doble cara manifestada en la violencia (fuerza física) o en la intimidación (psicológica). Ambas aparecen claramente diferenciadas en nuestro ordenamiento jurídico. Así, en el vigente Código Penal, no son pocos los artículos que las diferencian, aunque en la mayor parte de los casos tengan similar sanción. En efecto, se habla de «engaño o intimidación», de «fuerza, violencia, intimidación o amenaza», de «intimidación grave o violencia», de «intimidación o engaño», entre otros. ${ }^{2}$ Nuestro Código Civil sigue la misma línea al distinguir ambos conceptos: el artículo 1265 diferencia entre «error, violencia, intimidación o dolo» para referirse a las causas de nulidad del consentimiento; el art. 1267 define violencia e intimidación, tal que la primera se asocia a la «fuerza irresistible» y la segunda se concreta en inspirar a uno de los contratantes «temor racional y fundado de sufrir un mal inminente y grave en su persona o bienes, o en la persona o bienes de su cónyuge, descendientes o ascendientes $\rangle^{3}$.

En derecho comparado europeo no hay unanimidad al respecto. Así, el Código Civil francés, en su artículo 1130, califica al error, al dolo y a la violencia como vicios del consentimiento, para, posteriormente, dar a la violencia una dimensión algo ambivalente al calificarla como presión, sin concretar su carácter físico o psíquico ${ }^{4}$. Por su parte, el Código Civil portugués establece una clara diferenciación entre la violencia («coacção física») y la intimidación

${ }^{2}$ Vid., entre otros, los artículos Art. 172 bis, 177 bis 1 y 11, 181.1, 183.2 y 4c, 183 ter, 202.2, 362 quinques y 498 de la Ley Orgánica 10/1995, de 23 de noviembre, del Código Penal (BOE núm. 281 de 24 de noviembre de 1995).

3 Otros preceptos diferencian también ambos conceptos: vid. los arts. 141 («error, violencia o intimidación»), 1268, 1301 o 1302, por ejemplo, del Real Decreto de 24 de julio de 1889 por el que se publica el Código Civil (Gaceta de Madrid núm. 206 de 25 de julio de 1889).

${ }^{4}$ Article 1130 de la Loi 1803-03-05 promulguée le 15 mars 1803 : «L'erreur, le dol et la violence vicient le consentement lorsqu'ils sont de telle nature que, sans eux, l'une des parties n'aurait pas contracté ou aurait contracté à des conditions substantiellement différentes». 
(«coacção moral») en sus artículos 246 y 255 respectivamente 5 . En cuanto al Código Civil alemán, éste se limita a declarar la_impgunabilidad de la voluntad contractual cuando ésta se ha expresado bajo amenaza (§ 123 BGB).

Tal y como destaca SOLÉ FELIU ${ }^{6}$, esta distinción lleva a que, por un lado, la violencia, como fuerza irresistible que anula totalmente la voluntad del sujeto y, por tanto, que hace desaparecer uno de los elementos esenciales del art. 1261 del $\mathrm{CC}^{7}$ (el consentimiento), tendría como consecuencia la nulidad radical del contrato ${ }^{8}$, mientras que, por otro lado, la consecuencia de la intimidación llevaría a la posibilidad de anular el contrato por parte del intimidado. Esta postura no es pacífica ya que parte de la doctrina ${ }^{9}$ considera que la violencia, al tratarse de un vicio del consentimiento, ha de atenerse a las reglas de la anulación contractual, lo que tiene especial relevancia en el acotamiento de la acción impugnatoria.

\section{LA MAGNITUD DE LA INTIMIDACIÓN EN EL ÁMBITO CIVIL}

En nuestro ordenamiento jurídico y ateniéndonos al ámbito estrictamente civil, para que la intimidación tenga las consecuencias del art. 1265 CC (consentimiento nulo) se exige que la misma inspire en el contratante que la

${ }^{5}$ Artigo 246 del Decreto-Lei núm. 47 344, de 25 de Novembro de 1966 (Falta de consciência da declaração e coacção física): «A declaração não produz qualquer efeito, se o declarante não tiver a consciência de fazer uma declaração negocial ou for coagido pela força física a emiti-la; mas, se a falta de consciência da declaração foi devida a culpa, fica o declarante obrigado a indemnizar o declaratário»;

Y el artigo $255^{\circ}$ (Coacção moral): "1. Diz-se feita sob coacção moral a declaração negocial determinada pelo receio de um mal de que o declarante foi ilicitamente ameaçado com o fim de obter dele a declaração. 2. A ameaça tanto pode respeitar à pessoa como à honra ou fazenda do declarante ou de terceiro. 3. Não constitui coacção a ameaça do exercício normal de um direito nem o simples temor reverencial».

6 SOLÉ FELIU, J. La intimidación o amenaza como vicio del consentimiento contractual: textos, principios europeos y propuestas de reforma en España, IDRET 4/16, p. 5.

7 Se emplearán las siguientes abreviaturas: CC-Código Civil; STS-Sentencia del Tribunal Supremo: Secc.-Sección; FD-Fundamento de derecho; FJ-Fundamento jurídico; AH-Antecedente de hecho; SJPI-Sentencia del Juzgado de Primera Instancia; SJM-Sentencia del Juzgado de lo Mercantil; SAP-Sentencia de la Audiencia Provincial; AATSAutos del Tribunal Supremo; IRPH-Índice de referencia de los préstamos hipotecarios.

${ }^{8}$ De esta opinión, Carrascosa López, Valentín, Pozo Arranz, Asunción y Rodríguez de Castro, Eduardo Pedro. 1996. «El consentimiento y sus vicios en los contratos perfeccionados a través de medios electrónicos». Informática y derecho: Revista iberoamericana de derecho informático, volumen 12: 1029.

9 Entre otros, vid. De Castro y Bravo, Federico y Vallet de Goytisolo, Juan. 1985. El negocio jurídico. Madrid: Editorial Civitas: 134. 
sufre un «temor racional y fundado de sufrir un mal inminente y grave en su persona o bienes, o en la persona o bienes de su cónyuge, descendientes o ascendientes». Es decir, el temor ha de tener una cierta base de racionalidad, de credibilidad, de posibilidad, tal que los temores irracionales, no creíbles o imposibles vetarían la posibilidad de alegar intimidación. Además, el mal posible ha de ser grave e inminente, ya sea en el propio contratante, ya sea en sus bienes o en los de su cónyuge, ascendientes o descendientes. Esta descripción de requisitos parece que reproduce de forma fidedigna el escenario de una reestructuración de deuda. En efecto, un cliente, ya sea particular o empresario, que no puede hacer frente a sus obligaciones de pago, acude a su entidad bancaria bajo una situación de enorme presión por la posibilidad de perder sus bienes hipotecados o tener que cerrar su negocio, lo cual extiende sus efectos a todo su entorno familiar. Es evidente, a la vista de las numerosas ejecuciones hipotecarias y embargos, que los requisitos del mencionado precepto gozan del escenario propicio para cumplirse: es un resultado creíble. Sin perjuicio de la regulación expuesta, la exigencia del temor inminente y grave ha sido matizada por la llamada teoría de la «alternativa razonable», que se tratará más adelante y que da un carácter más objetivo (tal y como destaca Del Olmo García ${ }^{10}$ )y económico a la valoración de la intimidación y de la consideración de la edad y circunstancias del intimidado del art. 1267 párrafo 3 del $\mathrm{CC}^{11}$.

Es importante destacar que el llamado «temor reverencial» nunca puede ser causa de intimidación, tal y como se recoge en el art. 1267 en su último párrafo. De esta manera y centrándonos en un ejemplo bancario, la ya caduca sumisión y exagerado respeto que se tenía a los antiguos directores de sucursal y que hacía que algunos clientes no se atreviesen a rechazar, por ejemplo, una tarjeta cuando el director ordenaba al empleado (dando por hecho la aceptación del cliente) que le «pidiese» una tarjeta de crédito, es un claro ejemplo de temor reverencial, no calificable por tanto de intimidatorio. En otros ordenamientos jurídicos europeos, como el portugués, se sigue esta misma línea al excluir de las amenazas ese respeto o miedo reverencial ${ }^{12}$. No obstante lo expuesto, el hecho de que un sujeto sea el causante de ese temor reverencial, no excluye que, adicionalmente, se pueda ejercer intimidación con todos los requisitos exigidos para viciar el consentimiento del destinatario, tal y como destaca

${ }^{10}$ Del Olmo García, 2003: 146.

11 Esta misma postura se sigue en el Código Civil francés, cuyo art. 1130, párr. $2^{\circ}$ reza: «Leur caractère determinant s'apprécie eu egard aux personnes et aux circunstances dans lesquelles le consentement a été donné»

12 Véase por ejemplo el Código Civil portugués: Artigo 255.3 del Decreto-Lei núm. 47 344, de 25 de Novembro de 1966: «Não constitui coacção a ameaça do exercício normal de um direito nem o simples temor reverencial». 
ARNAU MOYA ${ }^{13}$. Es bastante habitual en banca que, para operaciones de elevado importe, acuda a la negociación un director comercial o de zona para inspirar dicho temor reverencial en el cliente y lograr cerrar el negocio, lo cual no da lugar a vicio alguno. En ocasiones y con clientela de banca privada o directivos de empresas de cierto volumen, se trata simplemente de henchir el orgullo del cliente, sabedor de que tales cargos solo tienen contacto directo con los clientes más importantes.

Señala DEL OLMO GARCÍA ${ }^{14}$, sin perjuicio de los requisitos enumerados en el art. 1267 CC, que la intimidación tiene su base en «la exigencia de solo dos requisitos»: la antijuridicidad de la conducta temida («amenaza injusta») y la falta de alternativa razonable o falta de salida (que el amenazado se encuentre «sin más alternativa que consentir»), elementos que contempla la propuesta de Código Civil (Libros V y VI: De las Obligaciones y Contratos y Prescripción y Caducidad, respectivamente), elaborada por la Asociación de Profesores de Derecho Civil ${ }^{15}$.

La teoría de la alternativa razonable se recoge también en el art. II.-7:206 del Borrador del Marco Común de Referencia (Draft Common Frame of Reference, DCFR) cuando indica que «una amenaza no se considera que induce a celebrar el contrato si, atendiendo a las circunstancias, la parte amenazada tenía una alternativa razonable» ${ }^{16}$.

13 ARNAU MOYA, Federico. 2008-2009. «Lecciones de Derecho Civil II. Obligaciones y contratos». Publicacions de la Universitat Jaume I. Servei de Comunicació $i$ Publicacions, Colección: 159: «No obstante, habrá intimidación si esas personas, en vez de inspirar un miedo reverencial están inspirando un temor racional y fundado de un mal grave e inminente».

${ }^{14}$ Así, aclara: «Estamos ante un caso de intimidación, cuando la amenaza injusta de una parte deja a la otra sin más alternativa razonable que consentir». Vid. Del Olmo García, Pedro. 2019. «Diez minutos de intimidación, como vicio del consentimiento novatorio». Almacén de derecho, Jun 18, Derecho Civil.

Acceso el 4 de diciembre de 2019. https://almacendederecho.org/diez-minutos-deintimidacion-como-vicio-del-consentimiento-novatorio/ y 2003. La amenaza de incumplir un contrato como vicio del consentimiento, Valencia: Tirant lo Blanch: 27, 133 - 141 y $151-169$.

15 Se define la intimidación como la «amenaza injusta, que provoque un temor racional y fundado de un mal inminente y grave, de acuerdo a las circunstancias, incluidas la edad y condición de la persona; siempre y cuando no haya tenido una alternativa razonable a la perfección del contrato», art. 527-8 en Ataz López, Joaquín y González Pacanowska, Isabel. 2016. «Libro V, Título II: De los contratos en general». En Propuesta de Código Civil. Libros Quinto y Sexto, Asociación de Profesores de Derecho Civil, Valencia: Tirant lo Blanch, http://www.derechocivil.net/images/libros/obra_completa.pdf, acceso: 12/12/2019.

${ }_{16}$ Proyecto del Marco Común de Referencia elaborado por el grupo de expertos designado por la decisión 2010/233/EU de la Comisión Europea el 26 de abril de 2010 
Respecto a la antijuridicidad, el Tribunal Supremo es claro al exigir, para que haya intimidación, la constancia o certeza de una conducta (amenaza) injusta o ilícita. Es decir, hay una doble exigencia: fáctica y jurídica. La primera hace referencia a la certeza o prueba de la existencia de la acción y la segunda se refiere a la calificación de la misma, a la calificación jurídica de la conducta ${ }^{17}$. El propio Alto Tribunal exige, respecto a la prueba, que no sea una mera conjetura ${ }^{18} \mathrm{y}$ que la «vis compulsiva» se pruebe siempre de forma irrefutable ${ }^{19}$; dicho en otros términos, la libertad de consentimiento se presume, tal que la carga de la prueba recae en quien la niega ${ }^{20}$.En cuanto al carácter ilícito, el Tribunal Supremo niega la ilicitud del mal o resultado no deseado cuando este sea la consecuencia del ejercicio de una facultad legítima o derecho ${ }^{21}$. No obstante lo anterior, la propia jurisprudencia del Supremo exige que el ejercicio de ese derecho sea correcto y no sea abusivo. Es decir, la licitud de una facultad o derecho no extingue necesariamente la posibilidad de existencia de intimidación ${ }^{22}$. A este respecto, el Alto Tribunal exige que la conducta no sea desproporcionada ${ }^{23}$, por lo que serán

(DUE 27de abril de 2010), citado aquí según la traducción ofrecida por JEREZ DELGADO, C. 2015. «Principios, definiciones y reglas de un derecho civil europeo: el Marco Común de Referencia (DCFR)». Madrid: Boletín Oficial del Estado.

${ }_{17}$ STS, Civil, Secc. $1^{\text {a }}, 790 / 2005$, de 21 de octubre, FD $3^{\circ}$, párrafo $3^{\circ}$.

${ }^{18}$ La STS, Civil, Secc. $1^{\mathrm{a}}$, 1162/2000, de 1 de diciembre, reza en el párr. $4^{\circ}$ de su FJ $1^{\circ}$ : «Aún cuando esta Sala ha dispuesto reiteradamente-sentencia de 17 de mayo de 1.988 y demás que esta recoge- que «el tema relativo a los vicios del consentimiento es una cuestión de hecho sometida a libre apreciación de los tribunales de instancia», no cabe olvidar que esa apreciación ha de estar fundamentada y no sostenida en meras conjeturas, de forma que la calificación jurídica que se atribuya a aquellos hechos o actos, que tienen que ser fundamentales, sea comprobable en casación según puede entenderse desde las sentencias de 6 de noviembre de 1.948 y 8 de febrero de 1.955 »

${ }^{19}$ La STS, Civil, Secc. $1^{\mathrm{a}}$, 1104/2000, de 25 de noviembre, establece en el párr. $4^{\circ}$ del FJ $1^{\circ}$ : «La «vis» compulsiva viciante necesita siempre prueba irrefutable», siguiendo consolidado criterio de previas sentencias: SSTS 184/1964, de 27 de febrero, 153/1970, de 31 de marzo, 744/1985, de 6 de diciembre y 291/1991, de 22 de abril, entre otras.

${ }^{20}$ La STS, Civil, Sección $1^{\text {a }}$, 744/1985, de 6 de diciembre, reza en su FJ $8^{\circ}:$ «[...]la libertad del consentimiento ha de presumirse $[\ldots]$ ».

${ }^{21}$ STS Civil, Secc. $1^{\mathrm{a}}$, 790/2005, de 21 de octubre, FD 3o párrafo $5^{\circ}$ y 744/1985, de 6 de diciembre de $1.985, \mathrm{FJ} 8^{\circ}$, entre otras.

${ }^{22}$ La STS, Civil, Secc. $1^{\text {a }} 163 / 1950$, de 21 de marzo establece en su considerando $2^{\circ}$ de sus FD: «si bien en ciertas ocasiones el ejercicio de aquella facultad [la de promover un procedimiento judicial contra la persona a quien se pretende intimidar] es justa y legítima por constituir un derecho de quien anuncia su utilización que por una u otra vía pretende obtener lo que le es debido, en otras se convierte en un verdadero chantaje con trascendencia notoria en distinta esfera jurisdiccional».

${ }^{23}$ Vid. la STS Civil, Sección 1a, 790/2005, de 21 de octubre. En este caso, un empleado dispone ilícitamente de 40 millones de pesetas de la entidad en la que trabajaba (Ba- 
especialmente relevantes las exigencias de la entidad bancaria y las consecuencias anunciadas para el caso de que el cliente no acepte la contratación. Es decir, que la entidad acreedora exija reestructurar una deuda imposible de pagar bajo la presión de entrada en mora y posterior ejecución parece más que razonable y proporcionado. Sin embargo, en aquellos casos en que la presión de la entrada en mora es un mero instrumento para imponer al cliente la contratación de una serie de productos claramente onerosos para su economía entraría dentro de un uso ilegítimo; igualmente, en aquellos casos en los que se utilice la presión de la entrada en mora cuando hay opciones menos gravosas como, por ejemplo, el aumento de garantías, estaríamos ante un resultado claramente desproporcionado. Según se expondrá más adelante, hay que prestar especial atención a las exigencias de las entidades financieras en las negociaciones novatorias y en las transaccionales ${ }^{24}$, ya que se suele exigir a los clientes la contratación de productos que nada tienen que ver con la propia renovación (planes de pensiones, seguros, etc.).

Como ya se ha adelantado en este artículo, la falta de una alternativa razonable ${ }^{25}$ es necesariamente una conditio sine qua non para la existencia de intimidación. Este requisito es especialmente importante a la hora de interpretar la exigencia de «temor racional y fundado» en un sentido objetivo y económico. SOLÉ FELIU va más allá de una mera interpretación extensiva o económica del término temor al indicar que no es necesaria la existencia del mismo, sino que bastaría con la falta de una alternativa razonable, lo cual parece sensato habida cuenta de la subjetividad e indeterminación de la

nesto); ante ello, el banco propone como solución la firma de un préstamo hipotecario del mismo importe para su devolución a cambio de no ejercer acciones legales contra el mismo. El Alto Tribunal entiende que la carga hipotecaria no es una conducta o solución desproporcionada.

${ }^{24}$ Tal y como destaca la STS, Civil, Secc. $1^{\text {a }}$ 205/2019, de 11 de abril, se han de diferenciar las meras novaciones modificativas de los acuerdos transaccionales: el FD $3^{\circ} .4$ dice: «[...] ambos contratos no son novaciones sino transacciones $[\ldots] » \mathrm{y} «[\ldots]$ ambos contratos autodenominados «novación modificativa», en atención a su contenido y la causa que subyace a los mismos, merecen la consideración de transacciones y no de meras novaciones obligacionales $[\ldots]$ ».

${ }_{25}$ A este respecto, debería completarse la determinación de la mejor alternativa posible (MAAN) a través de las teorías actuales del BATNA («best alternative to a negotiated agreement»). V., como referencia, Sebenius, James K. 2017. «BATNA s in Negotiation: Common Errors and Three Kinds of «No»». Negotiation Journal, vol. 33, n 2: $89-99$. [https://www.hbs.edu/faculty/Publication\%20Files/17-055\%20forthcoming_31fcea009139-421a-b7f4-7c8b5c572805.pdf ; última consulta: 9/12/2019]. Si bien, tales alternativas deben ser contempladas desde la perspectiva del sujeto que da su consentimiento en el contrato, es decir, de forma subjetiva y retrotraída temporalmente al momento de la firma del contrato. 
exigencia de temor ${ }^{26}$. Esto permite dar a este requisito un carácter más objetivo, al menos en lo que se refiere a la intimidación en el ámbito económico, además de ajustarse más a los supuestos de intimidación en el marco de las relaciones entre personas jurídicas, donde el concepto temor tiene un encaje más difícil. Igualmente, el temor es un concepto indeterminado que presenta dificultades en lo que se refiere a la prueba del mismo. Esto es especialmente relevante cuando se ha de interpretar en base a la «la edad y a la condición de la persona» (art. 1267 párrafo $3^{\circ} \mathrm{CC}$ ); por el contrario, la ausencia de una alternativa razonable, al tener un carácter más objetivo que el temor, es más fácil de valorar en consonancia con la edad y condición del intimidado. En esta misma línea se encuentran la mayor parte del derecho comparado europeo $^{27}$, con alguna excepción.

Según destaca DEL OLMO GARCÍA ${ }^{28}$, la consideración de la existencia o no de una alternativa razonable no es una cuestión sencilla. Ante tal dificultad, se hace necesario acudir a la exigencia del art. $1267 \mathrm{CC}$, debiendo por tanto valorar la existencia o no de dicha alternativa razonable en base a la edad y condición de la persona, es decir, ateniéndonos a las circunstancias de cada caso. En efecto, las alternativas razonables no son las mismas, por ejemplo, si estamos ante un consumidor de edad muy avanzada y escasos recursos que ante una multinacional saneada y solvente. Mientras que el primero no dispone de la capacidad económica, conocimientos, tiempo, etc., la segunda dispone de un grupo propio de asesores, abogados, economistas, experiencia en litigios, etc. En definitiva, la exigencia del mencionado precepto hace referencia a la necesidad de valorar cada caso de forma particular e individualizada ${ }^{29}$.

Lo anteriormente expuesto nos lleva a determinar que la intensidad exigida para que haya intimidación es tanto menor cuanto mayor sea la vulnerabilidad del que la sufre en base a su edad y circunstancias, y viceversa. En efecto, un anciano sin recursos económicos, endeudado y con un cónyuge enfermo, por ejemplo, requiere un menor grado de intimidación (para que

26 SOLE FELIU 2016, 8.

27 SOLE FELIU 2016, 20: «Una característica común a los textos y principios internacionales es el abandono del «temor» como presupuesto de relevancia de la amenaza».

28 Del Olmo García, Pedro. 2014. «La renegociación de los contratos bajo amenaza (Un comentario a la STS de 29 de julio de 2013)». Anuario de Derecho Civil, Tomo LXVII, I: 322-323.

${ }^{29}$ Valga como ejemplo la STS 7454/2007, de 8 de noviembre, que en su FD 2 dice: «[...] tampoco por la edad y condición del esposo de la actora cabía apreciar intimidación, dado que «es un padre de familia con amplia experiencia en el ámbito mercantil, que según la propia parte demandante desempeñaba el puesto de jefe de ventas de la sociedad codemandada», constando además que anteriormente había sido contable de una empresa de calzados y luego intermediario en la venta de una promoción de viviendas». 
esta sea invalidante del consentimiento) que una persona de mediana edad, con capacidad económica y sin cargas familiares. La exigencia de una alternativa razonable como podría ser la defensa de sus derechos en vía judicial (civil) no puede ser la misma (habida cuenta de los plazos habituales hasta una resolución firme) para una persona nonagenaria que para alguien de mediana edad, por ejemplo. El Tribunal Supremo es claro al apreciar esta graduación al establecer que «el grado invalidante de la intimidación tiene que medirse en función de las circunstancias ambientales y personales de quien la sufre, siendo aquel tanto menor cuanto mejor sea la posición social, cultural y económica de quien se diga intimidado» ${ }^{30}$. Es decir, esta «teoría de la graduación» implica que el efecto invalidante de una conducta intimidatoria es menor cuanto mejor es la posición social, cultural y económica de quien la sufre. Yendo más allá, esta graduación ha de hacerse extensible a la capacidad y recursos económicos, sociales y culturales de quien coacciona, pues no tiene el mismo efecto invalidante una amenaza que proviene de un sujeto con recursos económicos, conocimientos jurídicos y buena posición social que si viene, por poner un ejemplo claro, de una persona sin recursos, de edad muy avanzada y muy baja posición social. De igual modo que no tendrá la misma entidad (y por tanto el mismo efecto invalidante del consentimiento) una amenaza que proviene de una pequeña empresa familiar, endeudada y en suspensión de pagos que la que es efectuada por una gran empresa, saneada y emitida a través de un despacho de abogados ${ }^{31}$. Además de lo anterior y sin perjuicio de que se haya de valorar de forma individualizada cada caso, puede llegar a ser relevante en algunos casos la «distancia» (social, cultural y económica, entre otros factores) entre la persona que amenaza y el amenazado para que el consentimiento se considere o no viciado: a menor distancia, menor efecto invalidante de la amenaza, y viceversa. En definitiva, se trata de que la prevalencia de una de las partes es determinante a la hora de concretar la intensidad intimidatoria necesaria para invalidar el consentimiento, lo cual no veta la posibilidad de intimidación entre partes en igual situación económica, social y cultural.

${ }^{30}$ FD 2 párrafo 2 de la STS 7454/2007, de 8 de noviembre. La teoría de la graduación también se sigue en la SSTS, Civil, Secc. $1^{\text {a }} 163 / 1950$, de 21 de marzo y 153/1970, de 21 de marzo, entre otras.

${ }^{31}$ La STS, Civil, Secc. $1^{\text {a }}, 5 / 1952$, de 03 de enero, establece como relevante para la consideración de la intimidación como invalidante del consentimiento, en su AH 7 que «el primer comprador de la casa especuló con la miseria ajena, prevaliéndose de ser persona experta y de desahogada posición económica». Así mismo, destaca en el otro extremo que «[...]; se impuso la coacción y la amenaza y hubo de ceder, arrastrando en su forzada decisión a su hermana y copropietaria $\mathrm{D}$ a Sofía; que pensaba que si $\mathrm{D}^{\mathrm{a}}$ Nieves, pobre y de avanzada edad, se veía envuelta en un procedimiento criminal, de que se le amenazaba, no a este nuevo infortunio sobreviviría». 
Aportando un aspecto interesante para la cuantificación de la alternativa razonable, LÓPEZ DÍAZ ${ }^{32}$ destaca que la existencia de esta va en consonancia con que haya una prestación de valor similar a la inicialmente pactada. Esta idea se ha de traducir, en el ámbito bancario, como una situación similar a la inicial en términos de riesgo, endeudamiento, productos contratados, costes (interés remuneratorio, comisiones de apertura, gastos de estudio, notariales, etc.) y garantías, entre otros. Es decir, que la similitud no se respetará cuando las alternativas que se presentan al cliente sean, por ejemplo, un producto de alto riesgo, o unos seguros innecesarios y de valor elevado ${ }^{33}$, o un endeudamiento en el que se incrementan desmesuradamente el tipo de interés y las comisiones ${ }^{34}$, o la pérdida total de su patrimonio debido a la entrada en mora y ejecución. La mencionada autora aclara que la existencia de una alternativa razonable presenta una doble dimensión: la extrajurídica o de mercado (por ejemplo, acudir a otro proveedor ${ }^{35}$ en caso de que el habitual amenace con no suministrar las piezas necesitadas) y la jurídica, referida a la posibilidad de exigir por medio de los tribunales el cumplimiento de las obligaciones contractuales; doble dimensión de la alternativa razonable que ya venía sosteniendo DEL OLMO GARCÍA ${ }^{36}$. Partiendo de lo dicho, cobra especial relevancia la ya mencionada exigencia del art. $1267 \mathrm{CC}$ de atender a las circunstancias de cada caso. Como ya se ha explicado y ejemplificado, la edad y la posición social, cultural y económica son determinantes para determinar la existencia o no de vicio invalidante en el consentimiento.

No solo la inviabilidad o la dificultad real de acceder a otras opciones ha de considerarse sino también el coste de oportunidad. En efecto, hay casos en los que el acudir a otra vía (ya sea de mercado o extrajurídica, ya sea jurídica), puede suponer la pérdida de una opción o recurso difícil o imposible de

${ }^{32}$ López Díaz, Patricia Verónica. 2018. «Las relaciones entre la tutela precontractual y contractual del acreedor: la conexión y la proyección-absorción». Revista de Derecho de la Pontificia Universidad Católica de Valparaíso, $\mathrm{n}^{\circ}$ 50: 83.

33 Aclaremos que, por ejemplo, un seguro de vida de prima única para una hipoteca de 200.000 euros puede oscilar entre los 10.000 y 15.000 euros dependiendo de la entidad, del plazo del préstamo hipotecario, de la edad y salud del contratante, entre otros factores.

${ }_{34}$ El tradicional argumento de las entidades financieras que una refinanciación o reestructuración de deuda ha de tener unos intereses remuneratorios mayores debido a que el riesgo de impago es mayor pierde validez cuando se convierte en una mera disculpa para elevar desmesuradamente los intereses remuneratorios y aumentar desproporcionadamente las garantías reales, así como para cargar a la ya maltrecha economía del cliente con comisiones elevadas y productos tan caros para el cliente como rentables para la entidad.

${ }^{35}$ Como se explicará más adelante, esta opción normalmente no es viable para un cliente que renegocia su deuda bancaria, pues normalmente se trata de situaciones que arrastran impagos y, por ello, son vetadas por posibles nuevas entidades financieras.

${ }^{36}$ Del Olmo García, 2003: 146: «si existía alguna alternativa de mercado y si el remedio jurídico disponible era un remedio adecuado». 
recuperar. Por ejemplo, el coste oportunidad sería excesivamente elevado si se pierde la financiación para una campaña electoral, si se pierde la matrícula para el inicio de un curso universitario o si se pierde el acceso a una oferta de compra de productos a un proveedor que está liquidando mercancia. Mucho más claro es el caso, como señala DEL OLMO GARCÍA ${ }^{37}$, de daños difícilmente reparables como serían los sufridos en el honor y la propia imagen. En consecuencia, ya no podría considerarse como razonable una alternativa que implicase un perjuicio de tal naturaleza.

La tesis de la falta de alternativa razonable es plenamente seguida por el Alto Tribunal. Es especialmente clara la STS de 3 de junio de $2019^{38}$,en donde se resuelve que, cuando los clientes de la entidad Caixa Catalunya aceptaron la oferta del Fondo de Garantía de Depósitos de cambiar las obligaciones subordinadas por acciones, no lo hicieron de forma voluntaria sino impuesta, ya que no existía una «alternativa razonable». El Tribunal Supremo es claro en la calificación del acto al indicar que se trató de un «acto impuesto», de un "canje obligatorio impuesto» ${ }^{39}$. Esta línea se ha venido siguiendo por la jurisprudencia del Supremo en diversas resoluciones ${ }^{40}$.

La doctrina o teoría de la «alternativa razonable» permite afirmar que la existencia de esta opción razonable rompe la causalidad entre la intimidación y el comportamiento del intimidado. Es evidente que ha de haber una relación de causalidad entre la intimidación y el consentimiento para que este esté viciado. En este sentido no hay nada novedoso: la causalidad es conditio sine qua non para la sanción jurídica. Lo relevante es que la teoría de la «alternativa razonable» facilita la comprobación de este nexo causal de forma negativa: si hay alternativa razonable (siempre valorando los requisitos de edad y circunstancias personales del art. $1267 \mathrm{CC}$ ), no hay nexo cau$\mathrm{sal}^{41}$. Esta apreciación es recogida por el Grupo de Estudio del Código Civil

${ }^{37}$ Del Olmo García 2003: 141-146

38 STS, Civil, Secc. $1^{\text {a }} 314 / 2019$, de 3 de junio.

${ }^{39} \mathrm{FD} 3^{\circ}$ párrafos $5^{\circ}$ y $7^{\mathrm{a}}$ respectivamente: «El canje obligatorio impuesto por el FROB a los inversores no es, desde luego, un acto facultativo que quepa atribuir a la mera voluntad de los recurrentes» $\mathrm{y}$ «Resulta palmario que a quien se le impuso administrativamente canjear sus obligaciones subordinadas por acciones no pueda imputársele posteriormente la realización de un acto propio en sentido jurídico (es decir, voluntario y dirigido a causar estado), ni tampoco que dicho acto impuesto revele de forma inequívoca una determinada voluntad».

40 ATS Civil, Secc. $1^{\text {a }}$, de 22 de mayo de 2019: Recursos 200/2017, 320/2017, 1968/2017, 522/2017 y 292/2017, STS, Civil, Secc. $1^{\text {a }}$, 677/2019, de 6 de marzo, STS, Civil, Secc. $1^{\text {a }}$, 130/2019, de 24 de enero, STS, Civil, Secc. $1^{\text {a }}$, 208/2018, de 31 de enero y STS, Civil, Secc. $1^{\text {a }}, 3753 / 2017$, de 25 de octubre, entre otras.

${ }^{41}$ No así en sentido positivo porque la falta de alternativa razonable no implica necesariamente la existencia de vicio del consentimiento ya que se necesitan más requisitos 
Europeo y el Grupo de Investigación del Derecho Privado Civil Europeo cuando indican que, en aquellos supuestos en que existiese alternativa razonable, la amenaza no se podría considerar la causa de la conducta, aclarando, no obstante, que la carga de la prueba de la existencia de una alternativa razonable recae en la parte que amenaza ${ }^{42}$. Ello facilita sobremanera la valoración de la causalidad, entre otras cosas porque la «alternativa razonable», como ya se ha dicho, tiene un carácter objetivo-económico que se concreta en la existencia de una alternativa de similar valor al pactado o al inicial. Así, por ejemplo, si la alternativa a un canje de acciones es la pérdida de todo ese capital mobiliario por disolución de la entidad, parece claro que no hay un valor similar al inicial o al pactado. Igual sería el caso si la alternativa a renovar un apalancamiento financiero ${ }^{43}$ era la pérdida, por bajada de la cotización bursátil, de un elevado porcentaje de valor de mercado del activo, etc.

Conviene recordar que la intimidación puede provenir tanto de la propia parte contratante como de un tercero, tal y como establece el art. $1268 \mathrm{CC}$, siendo irrelevante que participe o no en el negocio jurídico ${ }^{44}$. Tal y como señala SOLÉ FELIU ${ }^{45}$, hemos de distinguir entre amenaza directa (tiene su origen en la parte contractual beneficiada por el resultado de la intimidación) y amenaza indirecta (quien realiza la amenaza no es parte del negocio jurídico). En el caso de los empleados de banca, pese a que no son la persona jurídica que será parte del negocio, no cabe duda de que actúan en nombre y representación de la entidad financiera y, a todos los efectos y en un caso de

para que la intimidación sea invalidante del consentimiento.

42 VON BAR, C., CLIVE, E. y SCHULTE-NÖLKE, H. 2009. «Principles, definitions and model rules of European private law: draft common frame of reference (DCFR)». Munich: Sellier European Law Publishers: 527: «If there was a reasonable alternative, which suggests that the threat was not the real reason for the threatened party agreeing to the demand. The burden of proving that the threatened party had a reasonable alternative rests on the party making the threat».

${ }^{43}$ Financiación de compra de activos financieros. A lo largo de la década de los 2000 a 2010 fue muy habitual que las entidades financieras ofrecieran a sus clientes de banca personal (más de 60.000 euros) y banca privada (más de 500.000 euros) préstamos para compra de productos financieros, desde los menos complejos (acciones del IBEX) hasta los más complejos (productos estructurados cuya rentabilidad se supeditaba a condiciones suspensivas de alcance de valor). De esta manera, por ejemplo, a un cliente que disponía de acciones por valor de 100.000 euros, se le ofrecía financiación (a veces bajo la forma de póliza de crédito a veces bajo la forma de préstamo) para la compra de otros tantos títulos por similar importe, pignorándose los primeros. Así, el cliente pasaba a tener, en ese momento, 200.000 euros en acciones, de las que estaban pignoradas la mitad, y un crédito de 100.000 euros.

${ }_{44}$ Para un estudio pormenorizado de este supuesto, vid.: Sole Feliu. 2016: 24-26.

${ }^{45}$ Sole Feliu. 2016: 9 y 24-26. 
intimidación, se debe considerar que quien efectúa la intimidación es la propia entidad financiera.

\section{III.LA INTIMIDACIÓN EN ÁMBITO BANCARIO DE LA RENEGOCIACIÓN}

A primera vista, parece difícil hablar de intimidación en el ámbito de las relaciones entre clientes y entidades financieras, ya que esta se relaciona con palabras como temor, mal inminente, sufrir un mal, etc., lo cual parece complicado de atribuir a instituciones con establecimientos de atención al público en donde el trato suele ser cercano y educado. Y esta concepción no es extraña incluso en algún autor ${ }^{46}$. No en vano, para el que no ha trabajado en banca y para el que nunca ha tenido que hacer frente a una negociación complicada en tal ámbito (reestructuración de deuda, refinanciación o conversión de productos, por ejemplo) en una situación de debilidad financiera, la figura de la coacción es inconcebible. Pero nada más lejos de la realidad. De hecho, no sólo empleados sino también clientes en situación de extrema debilidad financiera pueden atestiguar que lo habitual ha sido imponer productos, subidas de tipos desmesuradas, comisiones sin un servicio que las justifique, etc. cuando el cliente no tiene más opción que aceptar, cuando la entidad es sabedora de que el cliente no tiene otra «alternativa razonable».

Respecto al origen de tales situaciones, cabe decir que los años de crisis ${ }^{47}$ han generado numerosos casos en los que determinadas financiaciones bancarias resultaban imposibles de afrontar, al menos en el plazo en que se habían planteado inicialmente. Y esto se ha dado tanto en el ámbito empresarial como en el de los consumidores. Tanto es así que antes de 2008 apenas era una persona (interventor o subdirector) la encargada de «gestionar» los

${ }^{46}$ Blanco García, Ana Isabel. 2017. «Deber de información y vicio del consentimiento en la venta de participaciones preferentes. ¿anulable en todo caso?», Actualidad Jurídica Iberoamericana, $\mathrm{n}^{\circ} 6$ : 323: «Debemos entender que, en el contexto que aquí nos ocupa, no cabe interpretar que el consentimiento es nulo por violencia o intimidación, pues no suele ser ese el proceder de las entidades de crédito aun a pesar de la cuestionabilidad de sus políticas comerciales».

${ }^{47}$ Para un estudio más profundo de la misma, vid. De la Lastra Peralta, Rosa María y Wood, Geoffrey. 2010. «The Crisis of 2007-09: Nature, Causes, and Reactions». Journal of International Economic Law, $\mathrm{n}^{\mathrm{o}}$ 13, Issue 3 - September: 531-550. Especialmente interesante es la comparativa que hace respecto de otras crisis y de las diferencias entre crisis de capital y crisis de liquidez. Vid. igualmente la perspectiva en materia de derechos humanos dada por FELICE, WILLIAM F. 2010. The global new deal: Economic and social human rights in world politics. Lanham, Maryland: Rowman \& Littlefield Publishers. Edición impresa. 
llamados «deudores a 30», «a 60» y «a 90 días» ${ }^{48}$. La morosidad se movía siempre por debajo del $2 \%$ en los años previos a $2008^{49}$ y las refinanciaciones eran algo poco común y normalmente en casos de muy mala suerte o muy mala gestión por parte del cliente. Sin embargo, a partir de 2008, el número de deudores en situación de mora se dispara y resulta inviable que un solo empleado por sucursal se encargue de tal gestión. Así las cosas y sin aún departamentos específicos, era habitual que se repartiesen listados en las reuniones matutinas de las 8:00 a.m. entre todos los empleados para que llamasen a los diferentes deudores a 30,60 y 90 días para ingresar. Algunas entidades acudían a «pólizas escoba» ${ }^{50}$ para verter los impagos de cada cliente y así evitar su entrada en mora, y el consiguiente «sangrado» en la cuenta de resultados de la entidad. Se trataba, en definitiva, de un verdadero fraude contable pues, en la mayoría de las ocasiones, la deuda que se iba vertiendo en tal producto se sabía irrecuperable y simplemente se trataba de prorrogar lo inevitable. Las entidades que utilizaron esta fórmula mostraban una mora pública muy inferior a la real, debido a la existencia de una «morosidad sumergida» esperando su turno para «salir a la luz» ${ }^{51}$. Tal fue el incremento del número de deudores en situación de impago que las entidades se vieron obligadas a crear verdaderas estructuras y departamentos dedicadas en exclusiva a la gestión de la mora y, en los últimos años, incluso departamentos encargados de dar salida al volumen ingente de inmuebles que habían pasado

${ }^{48}$ En la jerga bancaria se refiere a los clientes que presentan un retraso en el pago de hasta 30 , hasta 60 o hasta 90 días, respectivamente.

49 Vid. Maudos Villarroya, Joaquín. 2009. «La banca española ante la crisis financiera». Revista de Economía de Castilla La Mancha, nº 14: 42 - 44.

${ }^{50}$ Consistían en una cuenta de crédito, sin comisiones de apertura, mantenimiento, administración, ni renovación, ni gastos de estudio, que solían presentar un tipo remuneratorio en torno al 10\% y que se utilizaban para verter todos los impagados de un cliente. Cuando presentan garantía hipotecaria, reciben el nombre de «hipotecas de máximos». Interesante estudio sobre su posible nulidad es el realizado por ESPIGARES HUETE, J. C. 2016. «Las pólizas de afianzamiento general: «pólizas escoba», entre la validez y la nulidad (Auto del TS 11 de marzo de 2015 y SAP de Granada de 20 de diciembre de 2013)». Revista Lex Mercatoria. Doctrina, Praxis, Jurisprudencia y Legislación, $n^{\circ} 1$, no $1: 25-31$.

${ }^{51}$ La SJM Murcia, Secc. $2^{\text {a }}$, 26/2015, del 28 de enero, se refiere a la finalidad de este tipo de pólizas a decir que su «[...]única utilidad es la de cargar las liquidaciones derivadas de los impagos de operaciones [...]». Obvia esta sentencia un aspecto importante como es el anatocismo que se produce en las mismas, ya que los cargos son de liquidaciones completas (capital impagado, interese remuneratorios, intereses de demora y comisión de reclamación de deuda vencida), sobre las cuales, la nueva póliza aplica un interés que rondaba normalmente el 10\%. Este tipo de pólizas se recoge en otras sentencias como la SJPI no 4, Mercantil, Guadalajara, 179/2018, de 30 de mayo y la SJM, Pontevedra, $18 / 2015$, de 23 de diciembre, entre otras. 
a ser propiedad del banco, con lo que ello conllevaba (costes de comunidad e IBI, deterioro, ocupación, etc.).

Analizado el panorama apocalíptico para entidades y clientes, conviene aclarar que ninguna entidad desea que un cliente «pase a mora» (empleando el argot bancario). Siempre se hacía lo indecible para evitarlo y siempre las entidades estaban abiertas a reestructurar la deuda mediante diferentes fórmulas. Lo interesante es que nunca se filtró a los clientes la información de que el banco era y será siempre el primer interesado en evitar el pase a mora del cliente. Todo lo contrario, siempre se vendió como un esfuerzo y casi un favor del banco la reestructuración de la deuda, lo cual daba a la entidad una fuerza mayor aún en la reestructuración. Ello se veía favorecido por el hecho de que los contratos bancarios son fundamentalmente «contratos de adhesión» lo cual, tal y como indica SARAZÁ JIMENA ${ }^{52}$, supone un incremento de poder por parte del que impone las condiciones generales.

Como ya se ha adelantado, la intimidación encuentra su entorno más favorable en el seno de una renegociación contractual, es decir, cuando ya existen unos lazos de dependencia financiera del cliente al banco. La renegociación se muestra como un entorno más proclive a la intimidación, tal y como destaca DEL OLMO GARCÍA ${ }^{53}$. Por el contrario, cuando se trata de nuevas relaciones o clientes, los vicios del consentimiento más comunes son el error y el dolo. Así, por ejemplo, es fácil encontrar casos en los que el empleado de banca afirmaba que la contratación del seguro propuesto es requisito para la firma del contrato de préstamo hipotecario, cuando en realidad la ley solo exige un seguro contra incendios básico con la compañía que nosotros elijamos, sin que ello pueda suponer aumento del tipo de interés remuneratorio ${ }^{54}$. Es raro el caso en que el empleado avisa al cliente de que la contratación del seguro obligatorio de daños (seguro de hogar) puede hacerse con otra compañía. En algunos casos, dependiendo de entidad y empleado, se llegaba a ejercer tal presión sobre el cliente que esta se entronca dentro de las prácticas agresivas. Esta tendencia o técnica de venta agresiva (e ilícita) ha ido desapareciendo en los últimos años, al menos en el ámbito de los préstamos hipotecarios para compra de vivienda, para dar paso a los préstamos

52 «[...]incremento de poder de quien impone las condiciones generales de los contratos frente a quien debe aceptarlas»: SARAZÁ JIMENA, R. 1994. «La nulidad en los contratos de adhesión». En Cuadernos de Derecho Judicial. El negocio jurídico: la ineficacia del contrato. Consejo General del Poder Judicial: p. 14.

53 DEL OLMO GARCÍA 2019.

${ }_{54}$ Art. 8 de la Ley 2/1981, de 25 de marzo, de regulación del mercado hipotecario; art. 10 del Real Decreto 716/2009, de 24 de abril, por el que se desarrollan determinados aspectos de la Ley 2/1981, de 25 de marzo, de regulación del mercado hipotecario y otras normas del sistema hipotecario y financiero; y arts. 14.1 f y 17.1 .3 de la Ley 5/2019, de 15 de marzo, reguladora de los contratos de crédito inmobiliario. 
hipotecarios bonificados, en los que la contratación del producto en cuestión hace atractivo el tipo remuneratorio.

Cuando se produce una renegociación bancaria de deuda, esta puede desembocar tanto en modificación contractual estricta o novación (por ejemplo, incorporar un periodo de carencia a un préstamo ${ }^{55}$ o renovar una póliza de crédito) como en la sustitución de unos contratos por otros, lo cual no es jurídicamente una novación ${ }^{56}$. En las reestructuraciones de deuda, muchas veces se tiende a la cancelación y extinción total del contrato inicial para la formalización de uno nuevo con nuevos plazos, carencia, avalistas, diferentes condiciones financieras, etc. lo cual, aunque, como ya se ha dicho, no es una novación, sí genera las mismas circunstancias que favorecen la intimidación ${ }^{57}$.

En estas situaciones, los aumentos desmesurados de tipo de interés y comisiones, así como de garantías y productos anexos, además de encontrarse en el límite de la prohibición de fijación unilateral del precio del art. 1449 del Código Civil ${ }^{58}$, suelen aparecer bajo el falso paraguas del aumento del riesgo. El banco suele alegar que son una consecuencia lógica y legítima del aumento del riesgo. Sin embargo, esto no es cierto desde el mismo momento en que las reestructuraciones de deuda dan lugar a escenarios en los que el cliente pasa a depender totalmente de la entidad; y los tipos de interés, comisiones y productos disparan el coste financiero de la operación para el cliente. Este argumento pierde peso cuando hay una «sobregarantía» (al cliente se le hipoteca todo), un incremento desmesurado del interés remuneratorio y de las comisiones o la contratación de una lista interminable de productos. Muchas veces, no era rara la amenaza indirecta por parte del empleado de banca, cuando remitía al analista de riesgos (que nunca está de cara al público) como emisor de la exigencia: «desde el departamento de

${ }^{55}$ La carencia implica la suspensión de la amortización del capital, tal que, durante un periodo denominado «carencia», el cliente solo paga intereses. Las carencias suelen ser por un periodo máximo de 2 años.

56 Vid. a este respecto la STS, Civil, Secc. 991 205/2018, del 11 de abril.

${ }^{57}$ La prioridad registral de las cargas reales (hipoteca, fundamentalmente) no se perdía debido a la existencia de las llamadas pólizas escoba, también llamadas pólizas en cobertura de riesgos, en donde se vertían todos los impagos del cliente, que provenían de sus diferentes contratos (leasing, cuenta de crédito, préstamo, etc.). La razón es que la garantía real se vinculaba tales pólizas y no a los mencionados contratos de origen.

58 Para un estudio más completo de este aspecto, vid. GARCÍA PÉREZ, C. L. 2017. «El contenido del contrato y la determinación del precio en la propuesta de Código Civil de la Asociación de Profesores de Derecho Civil (APDC)». En Anuario de derecho civil. vol. 70, no 3, editado por Ministerio de Justicia (http://www.mju.es/) y Boletín Oficial del Estado, BOE (http://www.boe.es), 1115 - 1121. Murcia: Fundación Séneca, Agencia de Ciencia y Tecnología de la Región de Murcia. 
riesgos me dicen que no es viable la renovación salvo que... contratemos ${ }^{59}$ este seguro (no exigido en la contratación inicial), aumentemos el tipo de interés (de forma exorbitada), paguemos comisión de renovación (injustificadamente alta), etc.».

En el ámbito de las prácticas bancarias agresivas, la frontera entre el dolo y la intimidación se hace difusa por la más que habitual concurrencia de ambas. Es evidente que la intimidación ha de ser mayor cuanto más grande es el perjuicio que sufre el intimidado. La amenaza ha de ser más intensa, más grave, más inminente cuanto mayor es el perjuicio. Así, para no tener que recurrir a un grado muy elevado de intimidación, el comercial solía acompañar a la misma del dolo en lo que se refiere al producto a contratar bajo coacción. En efecto, eran habituales las promesas imposibles para lograr la contratación de un seguro, de una tarjeta, de un fondo de inversión ${ }^{60} \mathrm{o}$ de un SWAP bajo la falsa promesa de que eso influiría en un tipo de interés más ventajoso, o bajo el engaño de que el fondo de inversión le reportaría ciertos beneficios o cuando se le decía que el swap fijaría su tipo de interés para protegerlo de posibles subidas. Y todo ello se decía asegurando que no hay otra opción, que la operación se aprobaría solo bajo la condición de firmar todos esos productos y que la otra opción era la entrada en mora y la posterior ejecución y embargo del bien hipotecado. Por tanto, dolo e intimidación van muchas veces de la mano en la contratación bancaria.

Una reestructuración de deuda no es más que descongestionar o aumentar la liquidez del cliente en el corto plazo, para lo cual hay diversos mecanismos. Principalmente están: el periodo de carencia ${ }^{61}$, cuando la falta de liquidez del deudor es algo temporal y a corto plazo; y la reestructuración «a

${ }^{59}$ Es muy habitual como técnica de venta (y así se enseña en los cursos de formación) el uso de la primera persona del plural para mostrar una (falsa) empatía, para hacer creer al cliente que el empleado es parte, junto al cliente, de las decisiones del banco. Así, se usan fórmulas del tipo: «tenemos que», «nos piden», etc.

${ }^{60}$ Parece a primera vista un contrasentido la coexistencia de una refinanciación o reestructuración, que implica imposibilidad de hacer frente a las actuales cuotas por diferentes motivos (descenso en el sueldo, despido, gastos extraordinarios, etc.), con determinados productos como un fondo de inversión, una tarjeta o incluso una IPF pero era en realidad muy habitual cargar de productos al refinanciado para hacer números. Así, se le solían contratar un fondo de inversión de 600 euros (mínimo importe para la mayoría de los fondos), tarjetas que no se le entregan, etc. Incluso y para hacer números, se le abrían contratos de depósito de valores que quedaban vacíos, contratos de banca a distancia sin generar claves, etc.

${ }^{61}$ El resultado de la carencia es que la cuota mensual se reduce considerablemente durante ese periodo, pero la deuda total o «riesgo vivo» no se reduce, con lo que el coste financiero de la deuda aumenta para el cliente. Es decir, el cliente ha comprado liquidez a corto plazo a cambio aumentar el coste financiero de su deuda. Véase AAP León, Civil sección 2, 66/2017, de 30 de junio: «[...] se hace una mera reestructuración de la deuda, 
largo»», que implica el aumento del plazo de devolución de la deuda con la consiguiente reducción de la cuota mensual. Han sido habituales los casos en los que la cuenta de crédito perdía su naturaleza por estar siempre dispuesta en su totalidad, lo que generaba que la entidad prestamista la reconvirtiera en préstamo para ir «reduciendo el riesgo $0^{62}$ » progresivamente. En la mayor parte de las ocasiones se cancelaba el contrato originario para firmarse uno nuevo con las modificaciones oportunas, lo cual generaba un nuevo dies a quo en el cómputo de posibles acciones. A primera vista podría parecer que se renunciaba a la prioridad registral de la garantía real hipotecaria, pero esto no se daba. La razón es que las entidades financieras solo firmaban nuevo contrato y cancelaban el anterior en los casos (sobre todo en refinanciación empresarial) cuando la garantía real estaba vinculada a una hipoteca de máximos, que implica una garantía real genérica para todos los riesgos del cliente ${ }^{63}$.

Cuando el empresario o el consumidor acudía a la reestructuración, sabía que tenía que aceptar todo lo que le presentase el banco. Sin entrar en las causas de la reestructuración (mala gestión empresarial, mala fortuna, aumento de la competencia, la gran recesión ${ }^{64}$, etc.), la realidad es que, para lo único que se tenía en cuenta al cliente, era para determinar el importe mensual que podía ser asumido por el mismo (a veces, ni eso). El jefe de riesgos de la sucursal (en las oficinas pequeñas, el mismo director), se encargaba de elevar la propuesta del nuevo riesgo, con nuevas condiciones: un aumento del plazo de devolución obviamente, pero también un aumento de tipos y comisiones, así como una serie de productos que necesariamente debían acompañar a la reestructuración (seguros fundamentalmente) y un aumento de las garantías (más avalistas y nuevos bienes a hipotecar, sobre todo). Desde los departamentos de análisis de riesgos, poco había que hacer (estudiar) más que justificar el puesto mediante un aumento de los costes financieros para el cliente ${ }^{65}$. Obvia decir que, salvo que el deudor presentase un escrito en el que se solicitase la aplicación de la Ley 1/2013, de 14 de mayo, de medidas para reforzar la protección a los deudores hipotecarios, reestructuración de deuda y alquiler social, la entidad financiera nunca haría mención a la misma.

fijando un periodo de carencia comprendido entre el 4-10-2013 y 4-10-2015, durante el que únicamente había que abonar los intereses».

${ }_{62}$ Reducir el riesgo, en el argot bancario, significa disminuir la deuda pendiente o «riesgo vivo».

${ }_{63}$ Vid. nota a pie 53.

${ }^{64}$ Crisis financiera de ámbito mundial que comienza en 2007, diferente a la «Gran Depresión», que comienza con el crack del 29.

${ }^{65}$ Las propuestas de riesgos «elevadas» desde las sucursales a los departamentos de riesgos (para su estudio y aprobación o «devolución»), en la mayoría de las ocasiones, se ven modificadas al alza tanto en los tipos y comisiones como en los productos exigidos por parte de estos departamentos. 
Aprobada la propuesta con las oportunas modificaciones, se le presentaba la reestructuración al cliente con una ausencia total de negociación. Es más, la alternativa que se le daba al cliente era el «pase a mora» y la ejecución de las garantías reales con la consiguiente pérdida de sus bienes. El cliente debía firmar todo: seguros de vida, seguros de desempleo, tarjetas, condiciones financieras casi inasumibles, etc. El cliente no tenía otra alternativa razonable. Se puede decir que la facultad de elección del cliente desaparece, lo cual es necesario para considerar la existencia de intimidación ${ }^{66}$. Es cierto que la reestructuración de la deuda favorece los intereses del cliente, pero la reestructuración como tal no es objeto de controversia. La intimidación se ejerce sobre las condiciones financieras de la misma y los productos anexos que, como condición irrechazable, se ve obligado a firmar el cliente. Es en ese punto donde se produce el efecto requerido del resultado contrario a los intereses del intimidado.

Respecto a la asistencia letrada en un proceso de reestructuración de deuda ante una entidad financiera, no debe excluirse a priori la posibilidad de intimidación. En principio es poco probable que un cliente en situación totalmente precaria económicamente se valga de los servicios de un letrado para un asesoramiento que difícilmente podrá pagar. El Alto Tribunal considera en su sentencia de 21 de marzo de $1970^{67}$ que dicha intervención es un argumento a favor de la exclusión de la intimidación, pero, tal y como matiza en sentencia más reciente de 4 de octubre de $2002^{68}$, tal asistencia letrada no implica necesariamente un veto a la existencia de intimidación, sino que más bien se considera una circunstancia que dificulta pero no impide por sí sola la intimidación. Es decir, se debe valorar cada caso en concreto para determinar si tal asesoramiento rompe los requisitos de la intimidación en la emisión del consentimiento.

No obstante y como ya se ha adelantado, para el que haya sido partícipe de una reestructuración de deuda de un cliente de entidad financiera, el

${ }^{66}$ Véase al respecto lo que la STS Civil, Secc. $1^{\text {a }}$, 894/2002, de 4 de octubre, dice respecto de la intimidación en su $\mathrm{FD}^{\circ}$ párrafo $7^{\circ}$ : «es preciso que uno de los contratantes o persona que con él se relacione, valiéndose de un acto injusto y no del ejercicio correcto y no abusivo de un derecho, ejerza sobre el otro una coacción o fuerza moral de tal entidad que por la inminencia del daño que pueda producir y el perjuicio que hubiere de originar, influya sobre su ánimo induciéndole a emitir una declaración de voluntad no deseada y contraria a sus propios intereses»».

${ }^{67}$ En concreto la STS, Civil, Secc. ${ }^{\text {a }}$, 153/1970, de 21 de marzo, en su considerando $1^{\circ}$ dice: «[...] lo que unido a que la intervención del Letrado del recurrente en la redacción del expresado documento excluye la idea de la pretendida intimidación [...]». Véase que dice «unido a», lo cual excluye por definición que el Alto Tribunal establezca una relación de causalidad entre la asistencia letrada (por sí sola) y la exclusión de intimidación.

${ }^{68}$ STS Civil, Secc. $1^{\text {a }}, 894 / 2002$, de 4 de octubre. 
escenario es el de un cliente abatido que acude a la sucursal sin ninguna posibilidad de negociar y sin ningún tipo de asistencia. Es más, en los meses previos a ese día, las cuentas del cliente se encuentran totalmente bloqueadas por la existencia de cuotas impagadas. En el día de la ficticia negociación, el cliente normalmente ya se encuentra desde hace meses en el grupo, como mínimo, de los 60 días ${ }^{69}$; y cada movimiento de la cuenta es monitorizado y autorizado (o no) por la entidad financiera. Al cliente se le devuelven todos aquellos recibos no imprescindibles, sólo atendiendo los estrictamente necesarios para la supervivencia económica como cuotas a la seguridad social, autónomos, electricidad, nóminas de trabajadores, etc. En los casos más extremos se devuelve todo. El criterio para la devolución o no es que exista una cierta reposición de fondos (ingresos). Es decir, aunque el cliente se encuentre en situación de, por ejemplo, «60 días» de forma «crónica», si cada mes la cuenta sigue recibiendo ingresos, se le atenderán esos recibos. Sin embargo, si estamos ante un cliente carente ya totalmente de capacidad de generación de fondos, se dejarán de atender todos los recibos. En este panorama en el que el deudor hace mucho que perdió el timón de sus cuentas, se hace imposible pensar en que haya la más mínima capacidad de negociación.

No debemos olvidar los casos de particulares «atrapados» en productos financieros adquiridos vía apalancamiento, es decir, cuya compra se financió mediante préstamo personal o cuenta de crédito ${ }^{70}$. En estos casos y debido a la gran recesión de los últimos años, muchos clientes que financiaron la compra de acciones, productos estructurados ${ }^{71}$, etc. se vieron en una situación en donde su capacidad de negociación desaparecía por completo. En efecto, si un cliente, por ejemplo, aportaba 100.000 euros de fondos propios y el banco le financiaba con otros 100.000 euros para la contratación de un producto estructurado, la caída en picado del valor de los títulos hacía que ese cliente

${ }^{69}$ Vid. nota 45

${ }^{70}$ La SJPI n ${ }^{\circ} 17$ de Palma de Mallorca, 179/2014, de 9 de diciembre, en su FD $9^{\circ}$ recoge informe pericial en el que se describe el apalancamiento financiero: «apalancamiento de una inversión se produce por el uso de deuda para su financiación. Las operaciones apalancadas tienen la característica de potenciar los resultados de una inversión, tanto con respecto a los beneficios como, en su caso, también a las pérdidas».

${ }^{71}$ Bajo el término «producto estructurado» se ha denominado en sentido amplio todo contrato en el que existía un activo financiero subyacente (por ejemplo, acciones de Banco Santander) o varios (tipo rainbow) de cuya cotización se hacían depender los pagos al contratante. No obstante, en la mayoría de los casos nos encontrábamos ante CFA (contratos financiero atípicos) autocancelables, lo que implicaba que, si en un determinado tiempo (por ejemplo, tres años) el activo subyacente había bajado de un determinado valor, se cancelaba obligatoriamente y el cliente recibía las acciones al valor del momento final. A este respecto, véase la SAP de Madrid, Civil Secc. 11, 105/2019, de 06 de marzo, en su FD $24^{\circ}$. 
pasase a depender totalmente de la voluntad de la entidad prestamista. Imaginemos un escenario en el que las acciones subyacentes del estructurado hayan perdido un $70 \%$ de su valor. El cliente tiene una deuda de 100.000 euros y un capital mobiliario de 60.000 euros. El cliente no tiene más salidas que, bien perder 140.000 euros, bien someterse a todas las exigencias de la entidad prestamista para las sucesivas renovaciones del crédito (si se financió, como era habitual en estos casos, con una cuenta de crédito, la cual presenta un periodo de renovación anual). No cabe aceptar que la pérdida del $70 \%$ del capital de la operación sea una alternativa razonable. En estos casos, más frecuentes de lo que se conoce, el cliente debía aceptar todas las subidas de comisiones y tipos en las diferentes renovaciones, así como todos los productos (seguros, principalmente) que le exigía la entidad para renovar el riesgo (el crédito), pues la otra posibilidad era la pérdida de una enorme cantidad de dinero e, incluso, de sus propiedades en los casos en que existiese garantía hipotecaria ${ }^{72}$.

Para la calificación de abusiva de la cláusula de interés remuneratorio (y, por ende, del resto de condiciones financieras), es importante diferenciar los casos de simple renovación anual de riesgo de los casos de refinanciación/ reestructuración de deuda. En el primer caso, por ejemplo, la renovación de una cuenta de crédito para compra de activos financieros (acciones, por ejemplo), la subida del tipo de interés se debería ceñir solo a la subida del índice de referencia y el diferencial no debería ser diferente al inicialmente pactado, ya que se trata muchas veces de operaciones a largo plazo que han de permitir al inversor un margen amplio de tiempo para reaccionar ante los cambios de cotización. En estos casos, la falta de alternativa razonable puede ser la base de la existencia de una intimidación invalidante cuando al cliente inversor no le quedan más opciones que aceptar lo impuesto por la entidad financiera o vender con pérdidas (especialmente cuando las pérdidas son elevadas y la operación fue apalancada, ya que no solo perdería su inversión, sino que tendría que pagar la deuda financiera) ${ }^{73}$. Sin embargo, en las reestructuraciones de deuda sí es comprensible un interés remuneratorio moderadamente superior al que correspondería para una operación de préstamo sin carácter reestructurador de deuda ${ }^{74}$. Se deben considerar igualmente otras circunstan-

${ }^{72}$ Es cierto que en la contratación inicial del producto normalmente no se le pedía al cliente garantía hipotecaria alguna pero, ante la pérdida de valor del subyacente, las entidades exigían el aumento de garantia reales, lo cual se traducía en garantías hipotecarias sobre los bienes del cliente, siendo la otra opción la pérdida un elevado porcentaje de la inversión.

${ }^{73}$ Respecto al efecto potenciador del apalancamiento en las pérdidas, vid. nota 66.

${ }^{74}$ En este sentido se ha pronunciado la SAP de Santa Cruz de Tenerife, Civil, sección $4^{\mathrm{a}}, 220 / 2018$, del 19 de junio, en su FD $1^{\circ}$, 4, párrafo $2^{\circ}$ : «Para determinar si el interés 
cias como las garantías aportadas, tal que, ya sea un caso u otro, un aumento de garantías debería limitar el aumento del tipo de interés, puesto que tal aumento se basa en el mayor riesgo, el cual se reduce por el aumento de las garantías. Es especialmente clara la jurisprudencia al establecer que la existencia de garantías reales hace disminuir el riesgo de impago, por lo que difícilmente sería no abusivo un aumento significativo del tipo de interés que acompañase a un aumento de las garantías reales ${ }^{75}$.

\section{IV.CONCLUSIONES}

La Gran Recesión mundial, que afectó de lleno a España desde 2008, generó una situación novedosa hasta entonces: una ola de reclamaciones judiciales contra la banca comercial. Hasta ese momento, resultaba inconcebible que un cliente demandase a un banco porque se suponía que los contratos de tales entidades (todos de adhesión) no presentaban resquicios legales que dejasen margen a la reclamación. Era habitual decir que, si estaba firmado, nada se podía hacer. Sin embargo, la política de los bancos de atar todos los posibles flecos contractuales y el carácter innegociable de sus contratos, dieron lugar a situaciones de abuso en donde muchos clientes perdieron todo su dinero: preferentes, bonos convertibles, SWAPS, etc.

Estas situaciones daban lugar a reestructuraciones y renegociaciones en donde los clientes (particulares y empresas) se vieron sometidos a las exigencias imperativas de los bancos al llegar la inevitable reestructuración. Cuando la falta de liquidez «a corto» era insostenible o cuando sobrevenían los vencimientos de productos estructurados o de cuentas de crédito de apalancamiento financiero, los clientes se veían obligados a afrontar una desesperada situación

pactado es notablemente superior al normal, [...] (hay que considerar) el interés ofrecido habitualmente y en circunstancias similares en el mercado de las operaciones de referencia (préstamo personal, refinanciación, línea de crédito, tarjeta de crédito, etc.), apreciando además el mayor riesgo soportado por las entidades tenedoras de las cuentas bancarias a cuyo cargo se pagan, de manera que ha de establecerse una consideración global de las circunstancias existentes en la concesión del crédito, en especial, la correlación entre el riesgo y el interés remuneratorio. En este caso el préstamo se concedió para la refinanciación de varias deudas previas derivadas de operaciones fallidas y de créditos de tarjetas, que desde luego permite concluir en que no es el convenido un rédito superior al normal que se conceden en este tipo de préstamos»».

75 SAP Baleares, Civil, sección 3, 142/2013, del 26 de marzo «[...]ha de tenerse en cuenta si la operación cuenta o no con garantías y, en concreto, con garantía hipotecaria, dado que ésta hace disminuir el riesgo de impago». Pese a que se refiere solo a la hipoteca, es obvio que se ha de extender a la prenda ya que está, en el ámbito financiero, otorga una garantía mucho más eficaz por consistir en la pignoración de títulos o, incluso, dinero en depósito. 
en la que solo tenían dos alternativas: aceptar las exigencias del banco o perder todo o gran parte de su patrimonio. Era en ese momento cuando las entidades financieras impusieron, en muchos casos por intimidación, sus cláusulas contractuales y sus productos. Aprovecharon el desproporcionado desequilibrio que suponía que estos clientes quedaban a merced de sus exigencias contractuales, lo cual se veía favorecido o intensificado, como ya se ha indicado anteriormente, por la práctica de los contratos de adhesión.

Los Tribunales se han mostrado estrictos en el castigo de estas prácticas bancarias en los miles de procesos judiciales afrontados. Estos parecen no tener fin a corto plazo, pues, sin haber acabado aún la actual ola de reclamaciones (cláusulas suelo, vencimiento anticipado, intereses abusivos, etc.) se avecina una nueva si el Tribunal de Justicia de la Unión Europea se pronuncia, como parece desprenderse de las conclusiones del abogado general, a favor del consumidor en el sentido de exigir una información mucho más completa en la explicación del IRPH.

\section{BIBLIOGRAFÍA}

Arnau Moya, F. 2009. «Lecciones de Derecho Civil II. Obligaciones y contratos 2008-2009», Publicacions de la Universitat Jaume I. Servei de Comunicació $i$ Publicacions, Valencia: Colección Sapientia. Edición en PDF.

Asociación de Profesores de Derecho Civil. 2016. Propuesta de Código Civil. Libros Quinto y Sexto, Valencia: Tirant lo Blanch, http://www.derechocivil.net/ images/libros/obra_completa.pdf, acceso 12/12/2019.

BlanCo GaRCía, A.I. 2017. «Deber de información y vicio del consentimiento en la venta de participaciones preferentes. ¿anulable en todo caso?». Actualidad Jurídica Iberoamericana - IDIBE, $\mathrm{n}^{\circ} 6$ - feb: $319-325$.

Carrascosa López, V., Pozo Arranz, A. Y Rodríguez de Castro, E. P. 1996. «El consentimiento y sus vicios en los contratos perfeccionados a través de medios electrónicos. Informática y derecho: Revista iberoamericana de derecho informático, volumen 12: $1021-1031$.

De Castro y Bravo, F. Y Vallet de Goytisolo, J. 1985. El negocio jurídico. Madrid: Editorial Civitas.

De la Lastra Peralta, Rosa María y Wood, Geoffrey. 2010. «The Crisis of 2007 09: Nature, Causes, and Reactions». Journal of International Economic Law, $\mathrm{n}^{\circ}$ 13, Issue 3 - September: 531-550.

Del Olmo García, P. 2019. «Diez minutos de intimidación, como vicio del consentimiento novatorio». Almacén de derecho, Jun 18, Derecho Civil. Acceso el 4 de diciembre de 2019. https://almacendederecho.org/diez-minutos-de-intimidacioncomo-vicio-del-consentimiento-novatorio/

- 2003. «La amenaza de incumplir un contrato como vicio del consentimiento», Valencia: Tirant lo Blanch.

2014. «La renegociación de los contratos bajo amenaza (Un comentario a la STS de 29 de julio de 2013)». Anuario de Derecho Civil, $\mathrm{n}^{\circ} 67$ (1): 313 - 328. 
EsPigares Huete, J. C. 2016. «Las pólizas de afianzamiento general: «pólizas escoba», entre la validez y la nulidad (Auto del TS 11 de marzo de 2015 y SAP de Granada de 20 de diciembre de 2013)». Revista Lex Mercatoria. Doctrina, Praxis, Jurisprudencia y Legislación, $\mathrm{n}^{\mathrm{0}} 1$, no 1: 25 - 31.

FELICE, William F. 2010. The global new deal: Economic and social human rights in world politics. Lanham, Maryland: Rowman \& Littlefield Publishers. Edición impresa.

GARCÍA PÉREZ, C. L. 2017. «El contenido del contrato y la determinación del precio en la propuesta de Código Civil de la Asociación de Profesores de Derecho Civil (APDC)». En Anuario de derecho civil. vol. 70, no 3, editado por Ministerio de Justicia (http://www.mju.es/) y Boletín Oficial del Estado, BOE (http://www.boe. es), 1073-1137. Murcia: Fundación Séneca, Agencia de Ciencia y Tecnología de la Región de Murcia. Edición en PDF.

Gónzalez CARrasco, M. C. 2016. «STJUE 21.12.2016: retroactividad ¿absoluta? de efectos de la declaración de nulidad de cláusulas abusivas». Revista CESCO de Derecho de Consumo, $\mathrm{n}^{\mathrm{o}}$ 20: 37 - 41 .

Jerez Delgado, C. 2015. Principios, definiciones y reglas de un derecho civil europeo: el Marco Común de Referencia (DCFR). Madrid: Boletín Oficial del Estado.

LÓPEZ DÍAZ, P. V. 2018. «Las relaciones entre la tutela precontractual y contractual del acreedor: la conexión y la proyección-absorción». Revista de Derecho de la Pontificia Universidad Católica de Valparaíso, nº 50: 51 - 91.

Maudos Villarroya, J. 2009. «La banca española ante la crisis financiera». Revista de Economía de Castilla La Mancha, $\mathrm{n}^{\circ}$ 14: 31 - 54.

SARAZÁ JimenA, R. 1994. «La nulidad en los contratos de adhesión». En Cuadernos de Derecho Judicial. El negocio jurídico: la ineficacia del contrato. Consejo General del Poder Judicial: $11-58$.

Sebenius, J. K.: BATNAs. 2016. «Negotiation: Common Errors and Three Kinds of «No»», Negotiation Journal, vol. 33, n 2: 89 - 99 https://www.hbs.edu/faculty/ Publication\%20Files/17-055\%20forthcoming_31fcea00-9139-421a-b7f47c8b5c572805.pdf

Solé FeliU, Josep. 2016. «La intimidación o amenaza como vicio del consentimiento contractual: textos, principios europeos y propuestas de reforma en España». Indret 4.

Von Bar, C., Clive, E. y Schulte-Nölke, H. 2009. «Principles, definitions and model rules of European private law: draft common frame of reference (DCFR)». Munich: Sellier European Law Publishers.

\section{JURISPRUDENCIA}

STS 163/1950, de 21 de marzo

STS 5/1952, de 03 de enero

STS 163/1950, de 21 de marzo

STS 5/1952, de 03 de enero

STS 153/1970, de 21 de marzo

STS 744/1985, de 6 de diciembre 
STS 291/1991, de 22 de abril

STS $1104 / 2000$, de 25 de noviembre.

STS 1162/2000, de 1 de diciembre.

STS 894/2002, de 4 de octubre

STS 790/2005, de 21 de octubre.

STS 7454/2007, de 8 de noviembre

SJPI Guadalajara, 179/2008, de 30 de mayo

SAP Baleares 142/2013, del 26 de marzo

SJPI de Palma de Mallorca 179/2014, de 9 de diciembre

SJM Murcia 26/2015, del 28 de enero

SJM Pontevedra, 18/2015, de 23 de diciembre

STS 3753/2017, de 25 de octubre

SAP de Santa Cruz de Tenerife 220/2018, del 19 de junio

STS 130/2019, de 24 de enero

STS 208/2018, de 31 de enero

SAP de Madrid 105/2019, de 06 de marzo

STS 677/2019 de 6 de marzo

STS 205/2019, de 11 de abril

AATS de 22 de mayo de 2019

STS 314/2019 de 3 de junio 


\title{
LA INTIMIDACIÓN EN EL ÁMBITO BANCARIO COMO ILÍCITO AFECTANTE AL DERECHO CONSTITUCIONAL DE PROPIEDAD
}

\author{
Intimidation as cause of nullity in bank contracting
}

\author{
Rubén Pérez Cordón \\ Magistrado Suplente de la Audiencia Provincial de Zamora \\ Profesor - Tutor de la UNED \\ rubperez@lugo.uned.es
}

\begin{abstract}
Silvia Martínez Cantón
Magistrada - juez titular del Juzgado de Primera Instancia $n^{\circ} 2$ de León

Profesora titular de Derecho Internacional Privado y Derecho Procesal en la Universidad Internacional de la Rioja silvia.martinez@poderjudicial.es
\end{abstract}

http://dx.doi.org/10.18543/ed-68(2)-2020pp15-40

\section{Copyright}

Estudios de Deusto es una revista de acceso abierto, lo que significa que es de libre acceso en su integridad. Se permite su lectura, la búsqueda, descarga, distribución y reutilización legal en cualquier tipo de soporte sólo para fines no comerciales, sin la previa autorización del editor o el autor, siempre que la obra original sea debidamente citada y cualquier cambio en el original esté claramente indicado

Estudios de Deusto is an Open Access journal which means that it is free for full access, reading, search, download, distribution, and lawful reuse in any medium only for non-commercial purposes, without prior permission from the Publisher or the author; provided the original work is properly cited and any changes to the original are clearly indicated. 